\title{
Contribuição dos Projetosde MDL BRASILEIROSDA INDÚSTRIA DE ENERGIA PARA a Promoção de Tecnologias Limpas em Prol do Desenvolvimento Sustentável
}

José Célio Silveira Andrade

DautoremAdministraçãopdaUnivesidade

Feedal da Bahia- UFBA, Professor Adjunto

daUniversidadeFederal daBahia-UFBA clioandradk@superigcambr/ cdiosa@ufbabr

Antônio Costa Silva Júnior

MestreemEngenhariapdaUnivesidade Feebal daBahia- UFBA, Datorandbdb

ProgramaEngenhariaIndustrial (PEI) daUniversidadeFedeal daBahia antoniocostasivajunio@@hotmail.com

Kristian Brito Pasini Bahard emCiênia da Computaçãopda FaculdadeRuyBarbosa, Mestrandbem AdninistracãodaNPGA-UFBA kristianpasini@gmail.cm

\section{Luciano Ângelo Francisco} Karel Nápravnik Filho

MestreemAdministracãoEstratégica pdaUNIFACS, Pesquisadorda UniversidadeSalvador-UNIFACS luiananapramik@unifacsbr

Andréa Cardoso Ventura

MestreemAdministraçãopdaUnivesidade Feebral daBahia- UFBA, Datorandaem AdministraçãodaNPGA-UFBA andreventurassa@gmail.com 


\section{RESUMO}

Entre os instrumentos do Protocolo de Kyoto, apenas o Mecanismo de Desenvolvimento Limpo (MDL) permite a participação de países em desenvolvimento, sendo o Brasil um de seus principais proponentes. 0 presente artigo busca avaliar a contribuição dos projetos de MD L brasileiros, ligados à indústria de energia, para a promoção de tecnologias limpas em prol do desenvolvimento sustentável. A través da análise de 37 projetos, realizada com base em modelo teórico especialmente construído, verificou-se o baixo desenvolvimento de tecnologias e práticas de produção mais limpas, bem como a incipiente contribuição do MD L para o desenvolvimento sustentável no Brasil. Conclui-se que os projetos de MD L brasileiros avaliados estão longe de atingir o seu propósito fundamental de minimizar as mudanças climáticas e estimular um modelo de desenvolvimento mais limpo através da cooperação entre países industrializados e em desenvolvimento.

Palavras-chave: Mecanismo de Desenvolvimento Limpo (MDL). D esenvolvimento Sustentável. Transferência de Tecnologias. Tecnologias Limpas.

\section{ABSTRACT}

\begin{abstract}
Among the Kyoto Protod's instruments anly the Clean Dexlopment Mehanism(CDM) makes the participation of dadoping countries posible Brazil is one of themost impatant users Theartide's goal is toevaluatethecontribution of Brazilian CDM projets redated to theEnergy Industry for demn tehndogies and sustainabledadqument. Fromtheanalysis of 37prgetsit is possibleto condudethat this contribution remains incipient. Thus, considering that dean techndogy and demer production are themost adequateenironmental stratejes toreah a sustainablededqument, it is not possibleto affirm that theseprgets are effetivedy contributingfor this tarct. So, at least in Brazil, CDM is far from adieingthefundamental purposeof minimizingthegdbal varming via thestimulation of a deaner dedopment modd relied on the coperation among cuntries
\end{abstract}

Key words: CleanDeadqument Meehanism(CDM), Clean Techndoges, Cleaner Production, Brazilian Enegy Industries 


\section{INTRODUÇÃO}

Temperaturas elevando-se ano a ano. Derretimento das calotas polares. Aumento do nível dos mares a ponto de cobrir ilhas inteiras. D escontrole dabiodiversidade terrestre. Essas vêm sendo algumas das previsões, ecoadas por cientistas, ambientalistas e até economistas nos quatro cantos do mundo, caso medidas eficazes de combate ao fenômeno climático denominado Aquecimento Global não sejam tomadas.

$\mathrm{O}$ aumento das emissões de Gases do E feito Estufa (GEE) na atmosfera da Terra, resultante do crescimento econômico e demográfico nos últimos séculos após a Revolução Industrial, está ocasionando alterações de temperaturas superiores à variação natural que sempre afetou o clima, causando-lhe uma mudança que se atribui ao "efeito estufa". Em 1988, para melhor entender esse fenômeno, a O rganização Meteorológica Mundial (MWO ) e o Programa das Nações Unidas para o Meio Ambiente (UNEP) criaram o Integovemmental Pand on Climate Change(IPCC) com o objetivo de reunir os principais cientistas do mundo para a elaboração de pesquisas científicas voltadas para o fornecimento de valorações, coordenadas à escala internacional, sobre 0 alcance, a cronologia e os efeitos potenciais da evolução do clima sobre o meio ambiente e as condições socioeconômicas (GRAU-NETO, 2007).

A partir dessas avaliações, em 1997, durante a 3a ${ }^{\text {Confe- }}$ rência das Partes (COP-3), a comunidade internacional criou 0 Protocolo de Kyoto, um acordo multilateral que estipula metas concretas de redução na emissão de GEE por parte dos países desenvolvidos, integrantes do Anexo I (VENTURA, 2008). Esse protocolo prevê mecanismos de flexibilização a serem utilizados para garantir o cumprimento dos compromissos da Convenção, a saber: a implementação conjunta (JI - Jaint Implemantation), que permite aos países industrializados compensarem suas emissões financiando projetos de redução em outros países industrializados; o Comércio de Emissões (CE), que permite aos países trocarem suas emissões permitidas; e os Mecanismos de D esenvolvimento Limpo (MDL), que permitem aos países industrializados o alcance de suas metas individuais por meio de projetos implantados em países em desenvolvimento (GO LD EMBERG, 2005, p. 178). 0 MD L torna-se especialmente importante no cenário mundial, tendo em vista ser o único que permite a participação dos países em desenvolvimento, ainda sem metas para o primeiro período de compromissos do Protocolo de Kyoto, que se encerra em 2012.

Para que as atividades propostas pelos projetos de MD L sejam consideradas elegíveis, devem-se observar alguns critérios fundamentais, entre os quais o da adicionalidade, que pressupõe a comprovação de efetiva redução da emissão de GEE e/ ou remoção de $\mathrm{CO}_{2}$ adicional ao que ocorreria na ausência do projeto e a contribuição do mesmo para o desenvolvimento sustentável do país onde venha a ser implementado, através da transferência de tecnologias ambientalmente seguras (VENTURA, 2008). Esses critérios foram definidos após longas negociações entre os países signatários do Protocolo, visando garantir não apenas a contribuição dos países em desenvolvimento para a minimização das mudanças climáticas globais, cujos grandes responsáveis são os países desenvolvidos ou industrializados, mas também a tentativa de incorporação de um novo modelo de desenvolvimento, com a real integração entre os países em prol de uma solução conjunta a uma problemática que atinge a todos, de formas diferenciadas.

A busca por alternativas para o desenvolvimento dos países de forma global e sustentável vem sendo praticada no âmbito das Nações Unidas, especialmente após a publicação do Relatório de Brundtland. 0 conceito não foi esquecido quando daformulação do Protocolo de Kyoto. Em seu artigo 10, que, por sua vez, reafirma os parágrafos 3, 5 e 7 da Convenção-Q uadro das Nações Unidas sobre Mudanças Climáticas (CQ NUMC), 0 acordo enfatiza a necessidade de cooperação entre países desenvolvidos e em desenvolvimento para atingir o seu objetivo principal: o cumprimento dos compromissos quantificados de limitação e redução de emissões de G EE, a fim de promover 0 desenvolvimento sustentável. Para tanto, faz-se necessária uma participação efetiva dos atores estatais e não-estatais (entre eles, os atores empresariais) de todos os países do mundo.

Vale destacar que se entende por desenvolvimento sustentável aquele que considera um crescimento econômico socialmente receptivo e com métodos favoráveis ao meio ambiente, conciliando objetivos sociais, ambientais e econômicos (SACHS, 2002). Portanto, os projetos de MDL devem demonstrar benefícios reais, mensuráveis e de longo prazo na busca de solução para a mudança do clima, de acordo com critérios estabelecidos pela Autoridade Nacional D esignada (AND) brasileira. O utro conceito importante neste estudo é o de tecnologia limpa, que tem como objetivo reduzir antecipadamente emissões prejudiciais ao meio ambiente, e cujo foco são as causas da degradação ambiental e não os seus efeitos. Sendo assim, as tecnologias limpas são fundadas no princípio de prevenção (LENZI, 2006) e valorizam o conceito dos 3Rs: redução, reutilização e reciclagem (LaGREGA et al., 1994). A partir da discussão dos dois conceitos anteriores, questiona-se a noção, preconizada pelo Protocolo de Kyoto, de transferência de tecnologias ambientalmente seguras, na qual knowhow equipamentos e tecnologias são compartilhados por stakehddesem prol da minimização dos efeitos humanos sobre o clima global (SERES, 2007).

Assim, considerando que um dos principais objetivos do MDL é fomentar o desenvolvimento sustentável nos países fora do Anexo I, mediante a transferência de tecnologias ambientalmente seguras, e partindo do pressuposto de que a geração de tecnologias limpas é a estratégia mais eficaz para o atingimento desses objetivos, este artigo partiu do seguinte problema de pesquisa: estará esse mecanismo sendo eficaz no fomento ao desenvolvimento sustentável e na geração de tecnologias limpas no Brasil?

Esta análise torna-se especialmente importante considerando-se que, atualmente, o Brasil é o terceiro maior proponente de projetos de MD L no mundo (11,33\%), estando atrás apenas da Índia (29\%) e China (27,3\%) (UNFCCC, 2009). No momento, os projetos brasileiros realizados concentram-se nos escopos setoriais da energia renovável (50\%), suinocultura (15\%) e substituição de combustível fóssil (13\%). A lém dessas atividades, estão sendo desenvolvidos projetos nas áreas de aterro sanitário, eficiênciaenergética, tratamento de resíduos, entre outras (MCT, 2009).

C CONTEXTUS Revista Contemporânea de Economia e Gestão. Vol.8 - № 1 - jan/ jun/ 2010. (07-20). 
Verifica-se, então, que os projetos enquadrados na categoria de Indústria de Energia, e mais especificamente os de busca por energias renováveis, representam a maioria das atividades de MDL realizadas no Brasil em prol da mitigação das mudanças climáticas globais. D essaforma, dever-se-ia esperar uma efetiva contribuição desses projetos para o desenvolvimento sustentável e para a geração de tecnologias limpas. Tendo em vista que o principal objetivo deste artigo é avaliar essa contribuição, espera-se estar ajudando a preencher uma lacuna existente no Brasil sobre estudos acadêmicos que avaliam esse importante instrumento de governança do clima global. Para atingir o objetivo proposto, construiu-se um modelo teórico para análise dos dados coletados através dos procedimentos metodológicos descritos em detalhe no item 3 deste artigo: análise documental de 37 projetos, entrevistas semiestruturadas com gestores de projetos e visitas técnicas de campo a projetos representativos.

Assim, a estrutura deste artigo é composta por três partes, além desta introdução e das considerações finais. Na primeira parte, são apresentadas as consideraçõ es teóricas do artigo, constituídas pela discussão do conceito de tecnologias limpas e pelo questionamento da eficácia da transferência de tecnologias ambientalmente seguras para 0 atingimento do desenvolvimento sustentável dos países hospedeiros de projetos MD L, tomando como exemplo o caso do Brasil. Na segunda, são descritos o modelo de análise e os procedimentos metodológicos utilizados na pesquisa, enquanto na terceira parte são apresentados e interpretados os dados e os resultados encontrados.

\section{CONSIDERAÇÕES TEÓRICAS}

Considerando-se que este artigo tem como objetivo principal a avaliação da contribuição dos projetos brasileiros de MDL (da categoria de Indústria de Energia) para o desenvolvimento sustentável, mediante o fomento de tecnologias limpas, faz-se necessária a realização de uma breve incursão sobre os principais conceitos teóricos que dialogam com esse objetivo - desenvolvimento sustentável, transferência de tecnologia e tecnologias limpas -, verificando sua relação com as proposições presentes no Protocolo de Kyoto.

\subsection{D L: Instrumento de G eração de Tecnologias L impas em Prol do D esenvolvimento Sustentável?}

Desde a década de 60, o paradigma econômico neoclássico, pautado na produção voltada exclusivamente para obtenção do lucro, vem expondo suas falhas e externalidades. A través do crescimento industrial quantitativo descontrolado, houve consequências ambientais negativas claras, como o fenômeno da chuva ácida e do aquecimento global. Em ambos os casos, passou a ficar claro que não seria possível continuar usando 0 princípio básico do paradigma neoclássico, em que o meio ambiente é considerado fonte inesgotável e depositária universal (SILVA FILHO, 1999).

É nesse quadro que, no início da década de 70, verificouse o surgimento do marco inicial da busca do "desenvolvimento sustentável", prática utilizada com o intuito de trazer o equilíbrio necessário entre 0 crescimento econômico e a sustentabilidade das sociedades. Esse conceito está em cons- tante construção e aprimoramento, e foi consagrado em 1987, em documento intitulado Nosso Futuro Comum (OurCammon Future), elaborado pela Comissão Mundial de Meio Ambiente e D esenvolvimento (CMMAD), mais conhecido como Relatório Brundtland. Nele, a O NU reconhece a dificuldade em se alcançar esse novo modelo:

\begin{abstract}
Afinal, o D esenvolvimento Sustentável não é um estado permanente de harmonia, mas um processo de mudança no qual a exploração de recursos, a orientação dos investimentos, os rumos do desenvolvimento tecnológico e a mudança institucional estão de acordo $\mathrm{com}$ as necessidades atuais e futuras. Sabemos que esse não é um processo fácil, sem tropeços. Escolhas difíceis terão que ser feitas. Assim, em última análise, 0 D esenvolvimento Sustentável depende do processo político (O NU, 1987, apud NETO, 2004, p. 38).
\end{abstract}

A percepção em relação à urgência do problema do aquecimento global vem se difundindo entre diversos atores sociais. A pós a publicação, em 2006, do chamado Relatório Stern, retratando as consequências econômicas das mudanças climáticas, até mesmo economistas e chefes estatais, que costumavam tratar os problemas ambientais de forma marginal, vêm se preocupando com a temática. A questão vem se difundindo, também, entre os atores empresariais, traduzindo-se na necessidade dos setores produtivos de tratarem a relação entre negócios e meio ambiente através das seguintes estratégias: intemalização das externalidades ambientais negativas, redução dos custos de produção, otimização do uso dos recursos naturais, minimização da geração de resíduos, markeingverde de produtos e processos mais limpos.

O enfoque da gestão ambiental mudou, então, para além do controle da poluição, incorporando os conceitos de prevenção da poluição e produção mais limpa (KIPE RSTOK, 2002), passando, paulatinamente, a ser vista como uma oportunidade para investimento em modificações no processo, aperfeiçoamento da mão-de-obra, substituição de insumos, redução da geração de resíduos e racionalização de consumo dos recursos naturais, gerando ganhos de competitividade e legitimidade perante a sociedade. A gestão ambiental passou a fazer parte de uma nova preocupação com a sustentabilidade das operações das empresas e, como tal, deve refletir o poder ampliado delas, de modo a permitir, de fato, que se tornem parceiras do "desenvolvimento sustentável" (BARBIERI, 2004).

0 principal fator motivacional para as empresas mudarem sua percepção é a busca da sustentabilidade do negócio. Nesse aspecto, a expressão "sustentabilidade" é fundamentada na abordagem de Sachs (1993), que preconiza a existência de cinco faces da sustentabilidade (social, econômica, ecológica, espacial e cultural), as quais devem ser levadas em conta simultaneamente por qualquer iniciativa de planejamento do desenvolvimento, pois direciona a população mundial para ter a consciência de ser uma "civilização do ser", fazendo um contraponto com a atual, que apregoa a "civilização do ter" .

A preocupação com a gestão ambiental tem gerado uma dinâmica diferenciada nas organizações e nas nações onde elas selocalizam. Tal fato espelha, portanto, um reflexo dos contex- 
tos social, político e econômico de cada país. Carrieri (2001) argumenta que, nos países centrais, o desenvolvimento sustentável se configura como uma proposta voltada para melhoria da qualidade devida e para o aperfeiçoamento da proteção ambiental. Já nos países periféricos, em que problemas básicos como o da segurança alimentar ainda persistem, o desenvolvimento sustentável surge como uma proposta ampla, voltada para a resolução de problemas de produção e para o bem-estar social.

De acordo com Van Bellen (2002 apud PHILIPPI; ERD MANN , 2007), o surgimento do conceito de desenvolvimento sustentável tem sua mais longínqua origem no debate internacional sobre o próprio conceito de desenvolvimento. Ele estaria ancorado nas críticas às concepções restritivas do desenvolvimento, que dariam excessiva ênfase ao crescimento econômico, levando a desastres ambientais significativos e ao aumento das desigualdades sociais. D e acordo com os autores, essa crise paradigmática ocasionou o surgimento denovas concepções acerca do que seria o desenvolvimento, buscando a sustentabilidade, que passa a incluir outras dimensões como a social, a ecológica, a espacial e a cultural, sem excluir a dimensão econômica.

Frente à constatação da impossibilidade de manutenção desse sistema de crescimento socioeconômico, vem sendo adotado, paulatinamente, o prisma da sustentabilidade. Verifica-se a busca por uma mudança paradigmática, tanto no que concerne à oferta (produção) e à demanda (consumo), quanto à incorporação de variáveis eindicadores mais abrangentes de desenvolvimento e qualidade de vida, que possam garantir a preservação ambiental e a sobrevivência das gerações futuras.

Buarque (2003) acredita que a busca por um modelo de desenvolvimento sustentável no decorrer do tempo é imprescindível, sendo que a questão não deve versar sobre quanto temos de pagar para efetuar as transformações, mas, sim, quanto custará se não a fizermos, se falharmos. Obviamente, não há consenso sobre isso. A forma de utilização dos recursos naturais e da exploração do trabalho é assunto extremamente conflitivo. Há diversos interesses em jogo. Para Kuhn (2003), o desenvolvimento sustentável apresenta-se como um campo de disputa, exprimindo uma ideia em potencial, configurando-se em um processo de transição paradigmática, cuja duração é incerta.

Ainda que o novo paradigma traga consigo todas essas dimensões e seja utilizado com diversos sentidos pelos mais distintos atores sociais, é importante ressaltar, conforme relembram Milani e Keraguel (2007), a existência de certo consenso de que o conceito de desenvolvimento sustentável ancora-se no balanço existente entre as esferas ambiental, social e econômica, resguardando-se, ainda, a relação entre as presentes e futuras gerações. Para os autores, a evolução do conceito de desenvolvimento sustentável - desde sua concepção, na década de 1970, e, em particular, em sua implementação em nível global, a partir da Rio-92 - demonstra muitas contradições entre as ações políticas locais e internacionais. Citando Lipietz (1993), os autores afirmam que a aplicação do termo em âmbito planetário exige atores com pensamentos construídos sobre a relação local/ global e vice-versa, sustentando, ainda, simetricamente, as três dimensões - ambiental, social e econômica (MILANI; KERAGUEL, 2007).
A busca de alternativas para o desenvolvimento dos países, de forma sustentável, vem sendo praticada em âmbito global pelas Nações Unidas. O s conceitos de desenvolvimento sustentável e sustentabilidade não foram esquecidos quando da formulação do Protocolo de Kyoto. Com isso, o tratado especifica que todas as nações participantes e, consequentemente, os setores industriais a elas relacionados, busquem, continuamente, a criação de novas formas de realizarem suas atividades produtivas, minimizando os impactos ao meio ambiente, garantindo a redução de $\mathrm{GEE}$ ou a remoção de $\mathrm{CO}_{2}$ da atmosfera, observando, sempre, a contribuição dessas atividades para 0 desenvolvimento sustentável e primando pela transferência de tecnologias ambientalmente seguras entre os países.

O bserve-se que o tratado não explicita quais seriam as dimensões a serem observadas por cada país hospedeiro na avaliação da contribuição (ou não) dos projetos de MD L propostos para o desenvolvimento sustentável das localidades direta ou indiretamente impactadas pelas atividades a serem desenvolvidas. D essa forma, cada país teve que definir, por meio de sua Autoridade Nacional D esignada (AND ), os critérios a serem utilizados. Considerando-se que, conforme retratado, as principais definições do que viria a ser o desenvolvimento sustentável o alicerçam sobre aspectos econômicos, sociais e ambientais, foi elaborado, pela AND brasileira, um conjunto de cinco critérios básicos para os projetos de MDL, contemplando as seguintes dimensões (CIMGC, 2003):

a) Contribuição para a sustentabilidade ambiental local: procura avaliar a mitigação dos impactos ambientais locais (resíduos sólidos, efluentes líquidos, poluentes atmosféricos, entre outros) propiciada pelo projeto em comparação aos estimados no "cenário de referência", ou seja, na situação existente na ausência do projeto.

b) Contribuição para o desenvolvimento das condições de trabalho e a geração líquida de empregos: busca verificar o compromisso do projeto com responsabilidades sociais e trabalhistas, programas de saúde e educação, e defesa dos direitos civis. Verifica, também, as melhorias, no plano qualitativo e quantitativo, de empregos diretos e indiretos, comparando com o cenário de referência.

c) Contribuição para a distribuição de renda: analisa os efeitos diretos e indiretos sobre a qualidade de vida das populações de baixa renda, observando os benefícios socioeconômicos propiciados pelo projeto.

d) Contribuição para a capacitação e o desenvolvimento tecnológico: avalia o grau de inovação tecnológica do projeto, tanto em relação ao cenário de referência quanto às tecnologias empregadas, em atividades passíveis de comparação com as previstas no projeto. Verifica, também, a possibilidade de reprodução da tecnologia empregada.

e) Contribuição para a integração regional e a articulação com outros setores: essa medição pode ser realizada a partir da integração do projeto com outras atividades socioeconômicas na região de sua implantação.

Não faz parte do escopo deste trabalho discutir em detalhe os pré-requisitos elaborados pela CIMGC. Porém, utilizou-se esses pré-requisitos, juntamente com outros encontrados nalite- 
ratura, para a elaboração dos indicadores do modelo de análise, apresentado no item 3 deste artigo, visando verificar a contribuição dos projetos de MDL estudados para o desenvolvimento sustentável mediante o fomento de tecnologias limpas no Brasil.

\subsection{D a Transferência de Tecnologias AmbientalmenteSe- guras para o D esenvolvimento de Tecnologias Limpas: uma transição necessária}

Analisando-se 0 artigo 10 do Protocolo de Kyoto e, em particular, seu item (c), percebe-se que o elemento tecnologia está intrinsecamente ligado à questão do desenvolvimento sustentável, pois as partes devem:

Cooperar na promoção de modalidades efetivas para o desenvolvimento, a aplicação e a difusão, e tomar todas as medidas possíveis para promover, facilitar e financiar, conforme o caso, a transferência ou o acesso a tecnologias, know-how, práticas e processos ambientalmente seguros relativos à mudança do clima, em particular para os países em desenvolvimento, inclusive a formulação de políticas e programas para a transferência efetiva de tecnologias ambientalmente seguras que sejam de propriedade pública ou de domínio público e a criação, no setor privado, de um ambiente propício para promover e melhorar a transferência de tecnologias ambientalmente seguras e 0 acesso a elas (SENADO FEDERAL, 2004, p. 27).

Embora o Protocolo não deixe clara a definição de tecnologias ambientalmente seguras, para melhor entender como, segundo o Protocolo, a transferência de tecnologia pode auxiliar as partes a alcançarem o desenvolvimento sustentável, faz-se indispensável conceituar transferência de tecnologia nesse contexto. Segundo Seres (2007, p. 2-3), o IPCC define transferência de tecnologia como:

a broad set of processes covering the flows of knowhow, experience and equipment for mitigating and adapting to climate change amongst different stakeholders such as governments, private sector entities, financial institutions, non-governmental organizations (NGO's) and research/ education institutions.

Assim, a questão da transferência de tecnologia, há muito tempo presente na agenda ambiental global, desempenhando um papel central na ecopolítica Norte-Sul, normalmente carrega consigo a noção de cessão de conhecimentos dos mais desenvolvidos (países do Norte) ao menos desenvolvidos (países do Sul). Acredita-se que países com conhecimento e domínio já consolidados em tecnologias ambientalmente seguras deveriam transferi-los a países com pouca ou nenhuma capacidade tecnológica instalada nessa área, visando diminuir o fosso de conhecimento e capacitação tecnológica Norte-Sul (ESTY; IVANOVA, 2002; LE PRESTRE, 2005).

No entanto, esse conceito desconsidera as assimetrias existentes entre os países do Sul, no que se refere à capacitação e ao desenvolvimento tecnológico. Tais recursos diferem grandemente entre os países do Sul. Assim, quando trazido para a realidade brasileira - em que já se tem, em algumas áreas, uma capacidade tecnológica consolidada e/ ou em estágio avançado de consoli- dação (a exemplo de áreas como energias renováveis, biocombustíveis, biomassa, exploração de petróleo em águas ultraprofundas, entre outras) -, a noção de transferência de tecnologias ambientalmente seguras através de projetos de MDL perde sentido e pode acabar favorecendo o modelo anterior, centrado na exportação, pelo Norte, de tecnologias ultrapassadas do ponto de vista ambiental: as tecnologias end-ofpipe Isto é, tecnologias consideradas ambientalmente seguras, porém focadas no controle dapoluição e não naprevenção ena ecoeficiência dos recursos naturais, contribuindo muito pouco para o desenvolvimento sustentável dos países hospedeiros de projetos de MDL.

Assim, países como o Brasil teriam condições de influenciar na extensão dessa transferência tecnológica, fazendo com que os projetos de MDL contribuíssem de fato para o desenvolvimento conjunto de tecnologias limpas, focadas na prevenção da poluição e na ecoeficiência, e não na transferência de tecnologias, ditas ambientalmente seguras, porém baseadas no controle da poluição no end-of-pipee sem nenhum contéudo de inovação tecnológica, conforme demonstrado no Quadro Conceitual proposto pelo artigo (Figura 1), a seguir:

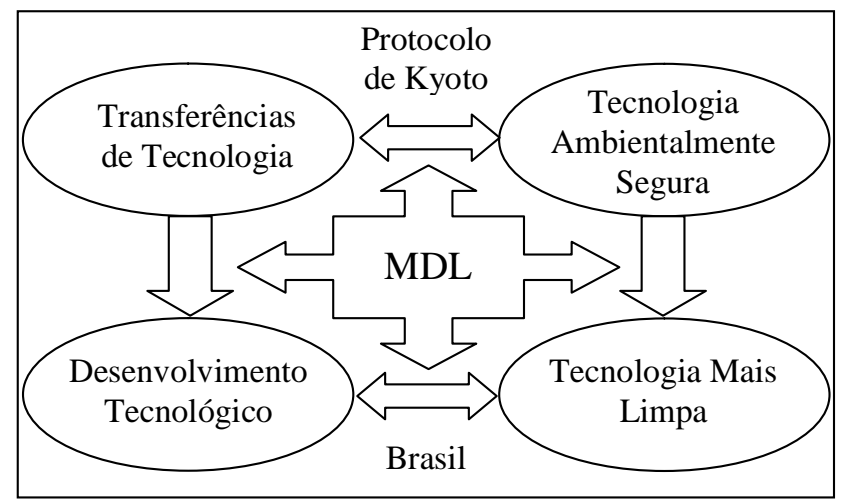

Figura 1: Q uadro Conceitual

Fonte: Elaborada pelos autores.

Esse argumento encontra respaldo nos resultados apresentados no Relatório Final de Dezembro de 2007, intitulado "Analysis of Technology Transferin CDM Projects", preparado por Stephen Seres (2007, p.4), ao apontar:

Brazil, China, India and South Korea - dominate the totals by sharing $72 \%$ of the projects (representing $80 \%$ of the annual emission reductions); Host countries can influence the extent of technology transfer involved in its CD M projects; Technology transfer is more likely for agriculture, $\mathrm{HFC}, \mathrm{N}_{2} \mathrm{O}$ projects and less likely for Biogas, Biomass energy, Cement, Coal bed/mine methane, Energy efficiency own generation, Energy distribution, Fossil fuel switch, Fugitive Hydro, Landfill gas, and Reforestation.

Diante do exposto, e considerando-se que o MD L pode tornar-se uma ferramenta promotora da concepção e do uso de tecnologias limpas em prol do desenvolvimento sustentável, principalmente nos países fora do Anexo I, discute-se, no item 2.3, a seguir, o conceito de tecnologias limpas. 


\subsection{D a tecnologia ambientalmente segura end-of-pipe para a tecnologia limpa: uma mudança indispensável em prol do desenvolvimento sustentável}

As tecnologias ambientais podem ser divididas entre tecnologias de controle de poluição enłof-pipee tecnologias limpas. As primeiras não alteram o sistema produtivo como tal, mas introduzem sistemas tecnológicos adicionais que capturam as emissões de poluentes a fim de diminuir o seu impacto sobre 0 ambiente. As tecnologias limpas, por sua vez, não buscam tratar a poluição após a sua emissão, mas tentam evitar ou reduzir tais emissões antecipadamente; focam as causas da degradação ambiental e não os efeitos. As tecnologias limpas são fundadas no princípio de prevenção, ao passo que as tecnologias end-of-pipe, também consideradas ambientalmente seguras, pautam-se no princípio de reação (LENZI, 2006).

Para o WBCSD (2006), o uso de tecnologias limpas pode ser entendido como uma aplicação contínua de uma estratégia técnica, econômica e ambiental integrada aos processos, produtos e serviços, a fim de aumentar a eficiência no uso das matérias-primas, da água e energia, pela não geração, minimização ou reciclagem de resíduos e emissões, com benefícios ambientais, de saúde ocupacional e econômicos. Sendo assim, as tecnologias limpas se caracterizam pela adoção de qualquer medida de mudança ou transformação de métodos utilizados para reduzir, ou melhor, eliminarjá na fonte a produção de qualquer tipo de poluição, e ao mesmo tempo racionalizar o uso de recursos naturais ou não. D essa forma, valoriza-se o conceito dos 3Rs: redução, reutilização e reciclagem.

Segundo Lagrega et al. (1994), a disposição da ordem dos 3Rs supracitados não éaleatória, pois quanto mais as tecnologias e práticas de produção limpa tendem para a redução de emissão de resíduos mais elas estarão ligadas à redução na fonte; serão transformações relevantes nas matrizes dos processos produtivos. Ao passo que quanto mais essas mesmas práticas atuem no tratamento dos resíduos do processo produtivo elas tenderão a práticas end-of-pipe

Essa afirmação pode ser melhor evidenciada pela Figura 2 , que demonstra os diversos tipos de estratégias ambientais que uma organização pode adotar para a redução da poluição. Q uanto mais a estratégia estiver focada para o lado direito do quadro as práticas tenderão a ser endof-pipe, ao passo que quanto mais a estratégia estiver focada para o lado esquerdo o processo estará altamente voltado para a redução de resíduos na fonte, colaborando, assim, para a produção, o consumo e o modelo de desenvolvimento mais sustentáveis.

Assim, as empresas, ao perseguirem a redução dos resíduos na fonte, tendem a inovar nos seus próprios processos produtivos, através de eliminação de perdas, reduzindo não somente os impactos ambientais como também os custos de produção. Logo, a difusão dessa estratégia inovativa levaria a uma maior utilização de tecnologias limpas, caracterizando uma situação de duplo dividendo, na qual as empresas tornar-se-iam mais competitivas, e toda a sociedade seria beneficiada com a redução de impactos ambientais (KIPERSTO K, 2003).

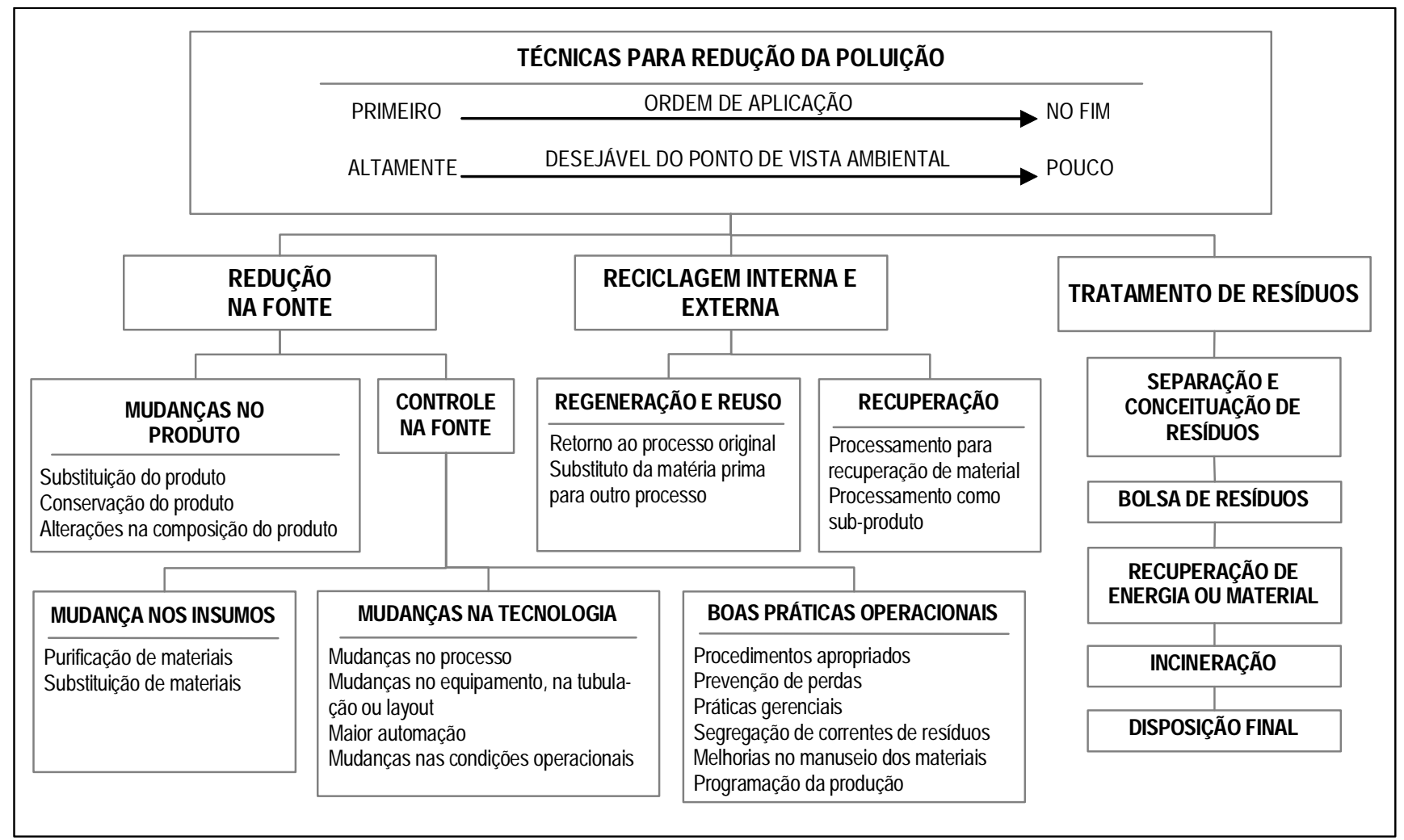

Figura 2: Técnicas para Redução da Poluição

Fonte: La G rega et al. (1994).

/ CONTEXTUS Revista Contemporânea de Economia e Gestão. Vol.8 - № 1 - jan/ jun/ 2010. (07-20).


Para efeito deste trabalho, a geração de tecnologias limpas só se caracterizase 0 aspecto da prevenção dapoluição for contemplado. Conforme Batista (1993), antes que novas e melhores tecnologias ambientais sejam uma constante no mercado, tem-se de passar por um período de mudança do antigo modelo tecnológico "endof-pppe", mesmo que ele ainda seja considerado ambientalmente seguro, para um novo modelo pautado em "tecnologias limpas", em favor do desenvolvimento sustentável.

Aliada aisso, deve-se considerar que a mudança tecnológica e organizacional ocasionada pela geração de tecnologias limpas, no nível das empresas e dos países, contribui para a resolução do dilema da compatibilização entre crescimento econômico e

\section{MODELO DE ANÁLISE E PROCEDIMENTOS METODOLÓGICOS}

Levando em consideração os conceitos apresentados nas considerações teóricas e os pré-requisitos do CIMG C para aprovação dos projetos de MD L no Brasil, construiu-se o modelo de análise da pesquisa (Figura 3). Conforme pode ser visto nessa figura, esse modelo representa os conceitos teóricos, as dimensões analíticas e os indicadores empíricos propostos para avaliar os projetos de MDL ligados à indústria brasileira de energia estudados nessa pesquisa.

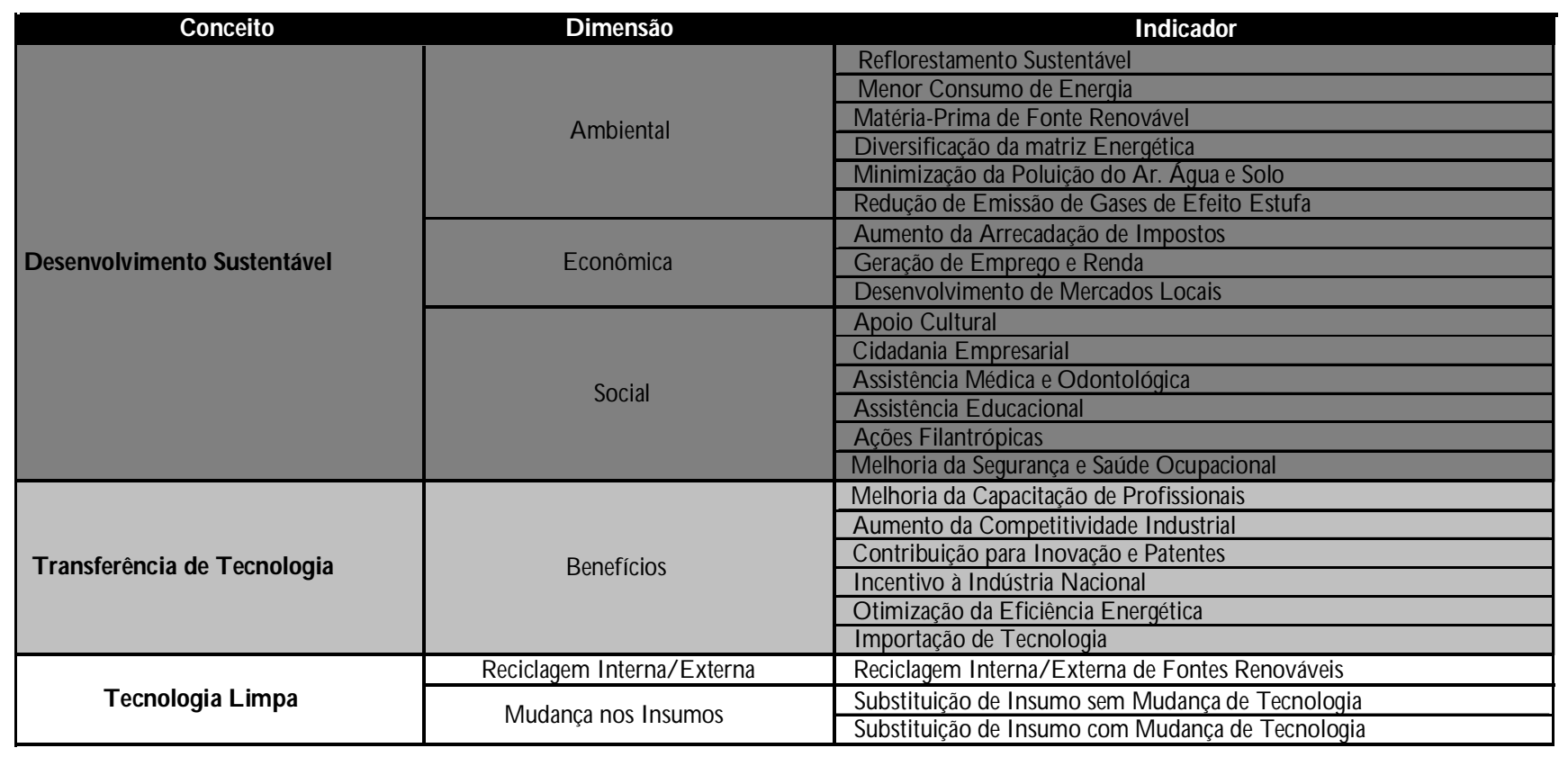

Figura 3: Modelo de análise da pesquisa

Fonte: Elaborada pelos autores

proteção ambiental. Logo, o MDL passaria a ser um instrumento de concretização de uma parceria público-privado. D essa forma, a sociedade ganharia com o desenvolvimento sustentável em suas três dimensões clássicas (social, ambiental e econômica), e, paralelamente, o setor privado ganharia com a exportação de um produto derivado de seu negócio principal: o carbonoexportação. Então, o MDL surgiria como alternativa viável para uma relação simbiótica entre interação do crescimento da economia e proteção do meio ambiente, que teria a tecnologia limpa como seu elemento indutor.

Sempre importante lembrar, conforme alerta Alberton (2003), que o desenvolvimento sustentável não nega a necessidade de as organizações gerarem lucros, serem rentáveis e crescerem. Porém, também é fato que tudo isso não pode ocorrer otimizando-se apenas os custos de produção e preços de mercado; é preciso também desenvolver a capacidade de se estruturare se organizar para produzir novos produtos e serviços economicamente viáveis, socialmente justos, ecologicamente sustentáveis, e com o uso de tecnologias limpas, e não só ambientalmente seguras, como apregoa o Protocolo.
Q uanto à natureza metodológica, optou-se neste trabalho por desenvolver uma pesquisa de cunho exploratónio, uma vez que ela possibilita o conhecimento do objeto como se apresenta, seu significado e o contexto em que se insere. Para tanto, utilizou-se as seguintes etapas operacionais: a) levantamento bibliográfico e documental para coleta de dados secundários, e b) realização de entrevistas semiestruturadas com gestores dosprojetos e visitas técnicas de campo para obtenção de dados primánios.

O levantamento documental foi utilizado especificamente para coletar os dados e as informações secundárias nos D ocumentos de Concepção de Projetos (D CPs) de todos os 37 projetos de MDL brasileiros classificados na categoria de indústria de energia, aprovados pelo Conselho Executivo de Projetos de MDL no Brasil, e que obtiveram a emissão de certificados de crédito de carbono pela United Nations Framenork Convention on Climate Change(UNFCCC) até 31 de dezembro de 2007. O s 37 D CP's selecionados para a elaboração deste artigo integram o projeto de pesquisa "A utilização dos projetos de mecanismos de desenvolvimento limpo pelas empresas brasileiras", financiado pelo Conselho Nacional de D esenvolvimento Científico e Tecnológico 
(CNPq) e executado em parceira com as seguintes Universidades: Universidade Federal da Bahia, Universidade Federal do Rio Grande do Sul e Fundação Getúlio Vargas do Rio de Janeiro.

Metodologicamente, o trabalho exigiu também a realização de entrevistas semiestruturadas com gestores de projetos, e visitas técnicas aosprojetos considerados representativos, objetivando coletar dados primários e confrontá-los com os dados secundários obtidos mediante a realização da análise dos DCPs, validando ou não aconsistência e coerência dessesprojetos.

Por fim, com base na pesquisa exploratória e no modelo analítico, procurou-se tratar os dados coletados por meio de técnicas quantitativas, através de estatística descritiva, com 0 objetivo de apresentar e interpretar os resultados obtidos, conforme pode ser visto no item 4 , a seguir.

\section{PROJETOSBRASILEIROSDA CATEGORIA INDÚS- TRIA DE ENERGIA:USO DE TECNOLOGIASLIMPAS EM PROL DO DESENVOLVIMENTO SUSTENTÁVEL?}

O s resultados aqui apresentados refletem a análise dos 37 projetos brasileiros de MD L citados. A categoria de indústria de energia - a que mais atrai a atenção do empresariado do País, visto que a busca por energias renováveis representa $50 \%$ dos projetos brasileiros de MDL - carrega consigo uma especial importância: a matriz energética adotada mundialmente, baseada fortemente em energias não renováveis como o petróleo e 0 carvão, é considerada uma das principais responsáveis pelo aquecimento global. Apresenta-se, inicialmente, uma breve caracterização dos projetos analisados.

Verifica-se que 76\% dos projetos de MDL brasileiros desse escopo setorial foram desenvolvidos na Região Sudeste, sendo $60 \%$ apenas no Estado de São Paulo. São fortemente focados em metodologias ligadas à cogeração de energia através do bagaço de cana, $65 \%$ do total de projetos, e na geração de energia através do gás natural, $24,5 \%$. Importante ressaltar que $94 \%$ dos projetos analisados foram realizados com apoio das empresas de consultoria Ecoenergy (51\%), Ecoinvest (30\%) eEcosecurities (13\%), e, em consequência dessa concentração, detectou-se sucessivas repetições de citações, afirmações e, principalmente, do processo descritivo da tecnologia implementada em cada projeto.

A pesquisa ratifica a constatação de Motta e Guimarães (2008) de que o segmento Kyoto do mercado de carbono éliderado pela União Europeia, cujos países membros foram responsáveis pela aquisição de $84 \%$ dos créditos gerados pelos projetos analisados, tendo destaque especial o Reino Unido (35\%) e a Suíça (24\%). Não se deve ignorar, no entanto, a participação dos países-ilhas Japão e Nova Z elândia, cada qual responsável pela compra de 13,5\% dos créditos gerados pelos projetos em análise.

O utro dado relevante é que apenas $8 \%$ dos projetos analisados foram contemplados com financiamento público. Esse dado torna-se ainda mais inquietante quando se observa a existência de linhas de financiamentos para itens essenciais à implantação desse tipo de projeto, a exemplo do Programa Nacional de Incentivo às Fontes Alternativas - PRO INFRA (BRASIL, 2008). E ssa poderia ser considerada uma fonte de recursos públicos essenciais para a implementação de projetos de MDL; no entanto, a alta burocracia envolvida (não apenas no Proinfra, mas nas regras da Agência Nacional de Energia - ANE EL, nos licenciamentos ambientais, entre outros controles) é citada por todas as empresas proponentes como uma das principais barreiras encontradas à proposição dos projetos. Entre outras barreiras citadas, encontram-se: a) os custos e riscos associados aos investimentos (89\%); b) a matriz energética atualmente dominante no País (78,5\%), visto que adquirir eletricidade não hidrelétrica ainda não é uma prioridade para o governo brasileiro; $c$ ) os riscos associados à inovação (62\%).

Já entre as principais motivações para a elaboração e implantação dos projetos, foram citadas: rentabilidade (81\%), fator descrito como crítico pela maioria das empresas pesquisadas, redução da emissão de gases (57\%), diminuição do risco de fornecimento de energia hidrelétrica devido à sazonalidade das chuvas (49\%), e diversificação das atividades da empresa (38\% ). Ressalta-se que apenas 13\% dos projetos citaram motivações de alguma forma relacionadas à promoção do desenvolvimento sustentável, a exemplo de melhorias socioambientais, aumento de empregos ou adoção de uma produção mais limpa.

Cabe, a partir desse dado, questionar os critérios de verificação adotados pela AND para analisar se esses projetos estão consistentes com seu duplo objetivo de redução de emissão de GEE e promoção do desenvolvimento sustentável, já que nenhum desses dois motivos é considerado um dos principais incentivadores para a adoção de projetos de MD L pelas empresas brasileiras pesquisadas.

Passa-se, agora, à análise dos três tópicos de maior interesse desta pesquisa: Transferência de Tecnologia, Tecnologias Limpas e Desenvolvimento Sustentável.

\subsection{T ransferência de Tecnologia}

Tendo-se como base as informações contidas no Anexo III de cada um dos 37 projetos analisados pela presente pesquisa, verificou-se que, no tocante a benefícios na área tecnológica, os principais aspectos levantados referem-se ao incentivo à indústria nacional, à capacitação de profissionais eà otimização do uso da energia do bagaço de cana, conforme pode ser visto na Figura 4.

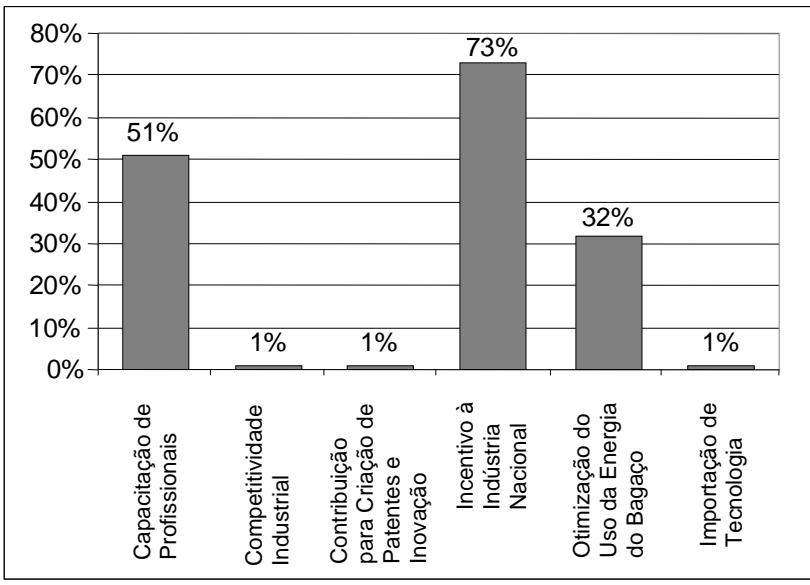

Figura 4: Benefícios: Aspecto Tecnológico

Fonte: Elaborada pelos autores 
Conforme se verifica na Figura, 73\% dos projetos analisados relatam que 0 "incentivo à indústria nacional" se dá em virtude das compras, no mercado nacional, dos equipamentos necessários para a implantação dos projetos de MDL, o que colabora para o crescimento da economia brasileira, sem apresentar, porém, grandes contribuições para o desenvolvimento tecnológico do País, já que grande parte dos equipamentos estava disponível para compra no mercado nacional. Consequentemente, o aspecto "capacitação de profissionais", com $51 \%$ de relatos, demonstra a necessidade de habilitar pessoas para operação e manutenção desses novos equipamentos, o que se deu pela transferência de conhecimentosjá dominados.

No que concerne ao benefício "otimização do uso da energia do bagaço de cana" (32\% dos relatos), vale salientar que essa perspectiva ocorre em virtude da maionia dos projetos estudados (65\% dos casos) estar ligadaà "cogeração de energia através do bagaço de cana”. Registra-se, dessa forma, o papel pioneiro do setor sucroalcooleiro para o desenvolvimento de MDL no Brasil.

Contudo, observa-se que os itens "importação de tecnologia", "contribuição para criação de patentes e inovação" e "competitividade industrial" foram citados por apenas $1 \%$ dos projetos pesquisados, fato que corrobora a ideia de que a transferência de tecnologia não foi preponderante, visto que, conforme discutido anteriormente, tanto os equipamentos quanto o knowhowe expertise para a operacionalização delesjá estavam disponíveis no Brasil. Consequentemente, houveuma incipiente contribuição dos projetos para criação de patentes/ inovações e aumento da competitividade industrial, itens nos quais o desenvolvimento de tecnologias limpas poderia contribuir substancialmente.

\subsection{Tecnologias Limpas}

De acordo com o artigo 12 do Protocolo de Kyoto, os projetos de MD L instituídos devem promover o desenvolvimento sustentável através do uso de formas novas e renováveis de energia, bem como de tecnologias ambientalmente seguras. Seguindo essa premissa, buscou-se classificar os projetos analisados de acordo com as estratégias tecnológicas e de produção mais limpa utilizadas para a geração de energia ou de otimização do processo, o que pode ser observado na Figura 5.

Pode-se notar que a maioria dos projetos analisados (65\%) transformou um resíduo oriundo da produção de álcool eaçúcar, o bagaço de cana, em matéria-prima renovável para a geração de energia. Contudo, verificou-se que todas as usinas sucroalcooleiras analisadas járealizavam esse tipo de reciclagem interna através de uma tecnologia de cogeração já dominada, visando serem autossuficientes em energia O MD L apenas contribuiu parauma maior expansão dessa estratégia de otimização do uso energético do bagaço de cana excedente, antes não totalmente aproveitado e considerado um resíduo de alto custo de disposição.

Portanto, o MDL surgiu como uma oportunidade econômico-financeira, uma vez que, além de tornar as usinas autossuficientes em energia, diversifica as suas atividades com a venda do excedente de energia, colaborando para uma melhor competitividade e imagem no mercado interno e externo. Essa afirmação se respalda na evidência de que em todos os projetos analisados para esse grupo os usineiros eram enfáticos em demonstrar que se não houvesse a compensação pecuniária do MDL não haveria motivação para a implantação da referida estratégia ambiental, principalmente por ser a matriz energética brasileira de fonte hídrica, ou seja, renovável, acessível e barata.

Ainda sob o prisma da reciclagem de biomassa para a geração de energia, evidenciam-se outros projetos (19\%) em que, diferentemente do observado nos projetos de cogeração de energia através do bagaço de cana - que também é um tipo de biomassa - , tinham uma fonte de energia baseada em combustíveis fósseis. Nesses casos, conforme indicado pela matriz de Lagrega et al. (1994), houve a substituição de um insumo não renovável por um outro renovável, contribuindo, assim, para a transição em direção a uma técnica para a redução de poluição altamente desejável do ponto de vista ambiental.

O utro grupo que merece destaque na Figura 5 são os projetos de cogeração de energia através do gás natural, que representam $11 \%$ dos projetos analisados, em quem ocorreu a mudança de um insumo originário de combustível fóssil para outro também de mesma origem (gás natural). Contudo, apesar de o insumo continuar sendo considerado não renovável, segundo a matriz de Lagrega et al. (1994), houve uma purificação na fonte, uma vez que a implantação do MD L nesses projetos proporcionou a introdução de um insumo menos poluente e de manuseio ambientalmente mais seguro.

Por fim, apesar de representar apenas $5 \%$ dos projetos estudados, o grupo dos projetos que revelam a substituição de um insumo não renovável por outro renovável merece ser realçado na presente pesquisa. A motivação para essa postura ocorre em virtude de que houve nos referidos projetos um duplo ganho na implementação do MDL, pois se conseguiu inovar a tecnologia bem como atender ao que é preconizado pelo Protocolo de Kyoto.

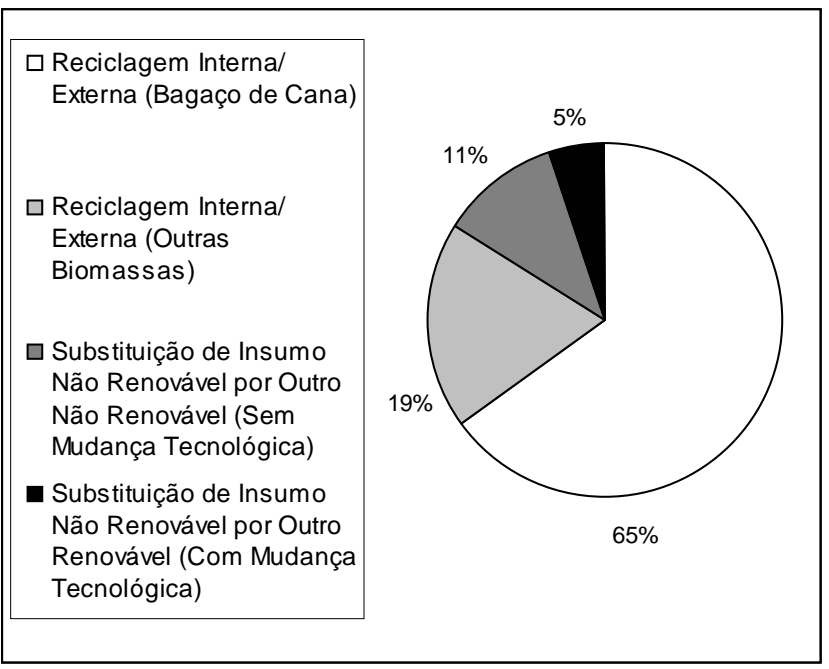

Figura 5: Estratégias tecnológicas de produção mais limpa utilizadas pelos projetos estudados

Fonte: Elaborada pelos autores 
Para melhor entendimento da relevância do que foi citado no parágrafo anterior, faz-se necessário discutir um dos dois projetos de MD L enquadrados nessa categoria: o Raudi Chemical Salts Project. A Raudi é uma empresa de capital fechado e de propósitos específicos, que se dedica à fabricação de produtos químicos e inorgânicos. Seu projeto consiste em produzir sais químicos, bicarbonato de sódio, bicarbonato de amônia e carbonato de cálcio, $\mathrm{com} \mathrm{CO}_{2}$ residual renovável, que era liberado anteriormente na atmosfera, proveniente da fermentação do suco de cana-de-açúcar de uma destilaria de etanol, localizada próxima à empresa, em lugar de um insumo antes originário de um combustível fóssil. Portanto, a iniciativa evita emissões de $\mathrm{CO}_{2}$ e contribui para o desenvolvimento sustentável ao estimular uma nova tecnologia que promove a redução da dependência de combustível fóssil na indústria química, substituindo-o por fontes renováveis. Nesse caso, de acordo com o que foi relatado no projeto, e à luz do conhecimento da matriz de Lagrega et al. (1994), houve uma transição a favor de uma técnica para a redução da poluição, uma vez que ocorreu uma redução na fonte através da mudança tecnológica. Logo, esse projeto atende aos pré-requisitos, no tocante ao desenvolvimento de tecnologias limpas, assim como pode vir a ser uma contribuição para o processo de transferência tecnológica em prol de padrões de consumo e produção sustentáveis.

Assim, ampliando essa perspectiva para os demais projetos, pode-se afirmar, segundo o critério da matriz de Lagrega discutida no item 2.3 deste artigo, que, apesar de o MD L possibilitar o desenvolvimento de tecnologias consideradas ambientalmente seguras, de todos os 37 projetos examinados
Vale salientar que esse quadro inicial, trazido no presente estudo, retrata uma situação de pioneirismo no desenvolvimento de projetos de MD L no Brasil na categoria Indústria de Energia. Portanto, espera-se que esse cenário caminhe para uma situação de crescimento de práticas de tecnologias focadas na produção mais limpa, e consecutivamente de declínio das tecnologias focadas na remediação e no controle da poluição através da reciclagem interna. Para que isso ocorra, nos projetos brasileiros de MD L ligados à industria de energia, é necessário atribuir à geração de tecnologias limpas um stausde maior importância para 0 atingimento do desenvolvimento sustentável.

\subsection{D esenvolvimento Sustentável}

No tocante ao Aspecto Ambiental, a Figura 6 abaixo mostra que em $57 \%$ dos projetos de MD L analisados afirma-se que a "minimização da poluição do ar, da água e do solo" é um dos principais aspectos ambientais positivos trazidos pelas alterações de processo adotadas. Em contrapartida, apenas $11 \%$ deles declaram a "redução da emissão de gases do efeito estufa" e somente $5 \%$ informam a "minimização das mudanças climáticas" como um dos impactos positivos trazidos ao meio ambiente. Essas mudanças climáticas deveriam ser, ao menos em tese, as principais contribuições esperadas de um projeto dessa natureza, especialmente se se considera que - nesse primeiro período de compromissos do Protocolo de Kyoto - a redução de GEE nos países em desenvolvimento é voluntária, visto que eles ainda não possuem metas de redução. Possivelmente, se a redução fosse obrigatória no Brasil, esses fatores seriam citados por um número significativo de empresas.

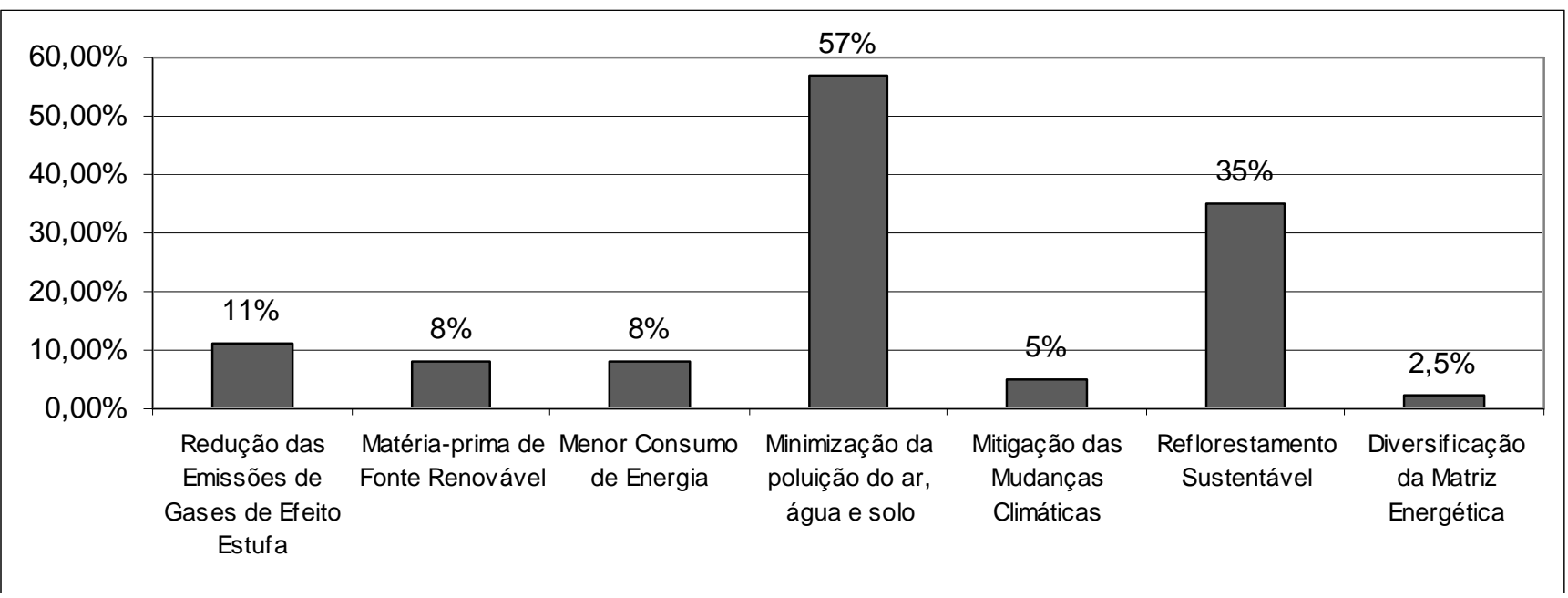

Figura 6: Benefícios: Aspecto Ambiental

Fonte: Elaborada pelos autores.

na presente pesquisa apenas $5 \%$ se caracterizam pela real aplicação de uma tecnologia focada na produção mais limpa. Cumpre ressaltar que nos demais projetos (95\%) houve a aplicação de uma tecnologia que transita entre um modelo de produção baseado em tecnologias ambientais end-of-pipee um novo modelo de incentivo a técnicas de redução da poluição na fonte, visando a uma produção mais limpa.
O bserva-se, ainda, que os demais aspectos ambientais citados não estão diretamente relacionados às atividades desenvolvidas nos projetos de MDL, mas, sim, a práticas ambientais das empresas pesquisadas em geral. Tome-se, por exemplo, 0 segundo item mais citado, o "reflorestamento sustentável" (com $35 \%$ das citações), que reúne afirmações sobre atividades de reflorestamento propriamente dito, e também sobre a "recupe- 
ração de bacias hidrográficas" ea "implantação de cinturõesverdes" . A leitura dos D CPs, as entrevistas e as visitas técnicas de campo deixaram claro que essas atividades não foram desenvolvidas dentro do escopo do projeto de MDL, mas sim como parte das ações de gestão ambiental da empresa.

Um outro aspecto a ser observado é a baixa contribuição dos projetos para a ecoeficiência das empresas que os propõem. A penas 8\% dos projetos citaram o "menor consumo de energia" como um aspecto ambiental positivo das alterações introduzidas, o mesmo percentual observado para uso de "matéria-prima de fonte renovável". D estaca-se, ainda, que somente um dos projetos (2,5\%) declarou a "diversificação da matriz energética" como um aspecto ambiental positivo.

Ressalta-se que 5,5\% dos projetos pesquisados representam atividades de queima de madeira de florestas plantadas de eucaliptos e/ ou pinus, e que a aceitação desse tipo de projeto, envolvendo o plantio de monoculturas florestais, é uma das principais críticas existentes por parte de grupos de ambientalistas contra os projetos de MD L (VENTURA, 2008).

Assim como observado nos A spectos Ambientais, também nos Aspectos Sociais (Figura 7) verifica-se uma grande tentativa das empresas proponentes em demonstrar à AND brasileira sua contribuição para o desenvolvimento sustentável.
O segundo item mais citado é a "assistência médica e odontológica" oferecida aos trabalhadores. Trata-se de um benefício ao trabalhador que, apesar de já ter sido incorporado à Convenção Coletiva de Trabalho de diversas categorias profissionais, ainda é pouco oferecido a trabalhadores do setor sucroalcooleiro brasileiro, considerado um dos mais exploradores do País. Dessa forma, em comparação com o cenário de referência, torna-se fácil às empresas proponentes demonstrarem melhorias realizadas na área de saúde.

O utro fato que merece destaque é que 14\% das empresas pesquisadas citam ações de "filantropia" como um dos principais impactos sociais obtidos. Trata-se do terceiro aspecto mais citado. O corre que práticas filantrópicas não são suficientes para assegurar a sustentabilidade de uma comunidade ou de um grupo de pessoas, conforme se depreende do conceito de desenvolvimento sustentável trazido no item 2.1. Na tentativa de complementar essa insuficiência, também foram relatadas ações de "cidadania empresarial" (5\%), e de "apoio cultural" (2\%). Um dos aspectos mais diretamente ligados a uma possível contribuição do projeto de MD L ao desenvolvimento sustentável da localidade onde está instalado éa " capacitação dos profissionais" envolvidos. Esse item foi citado por 51\% das empresas pesquisadas e está ligado às melhorias qualitativas dos traba-

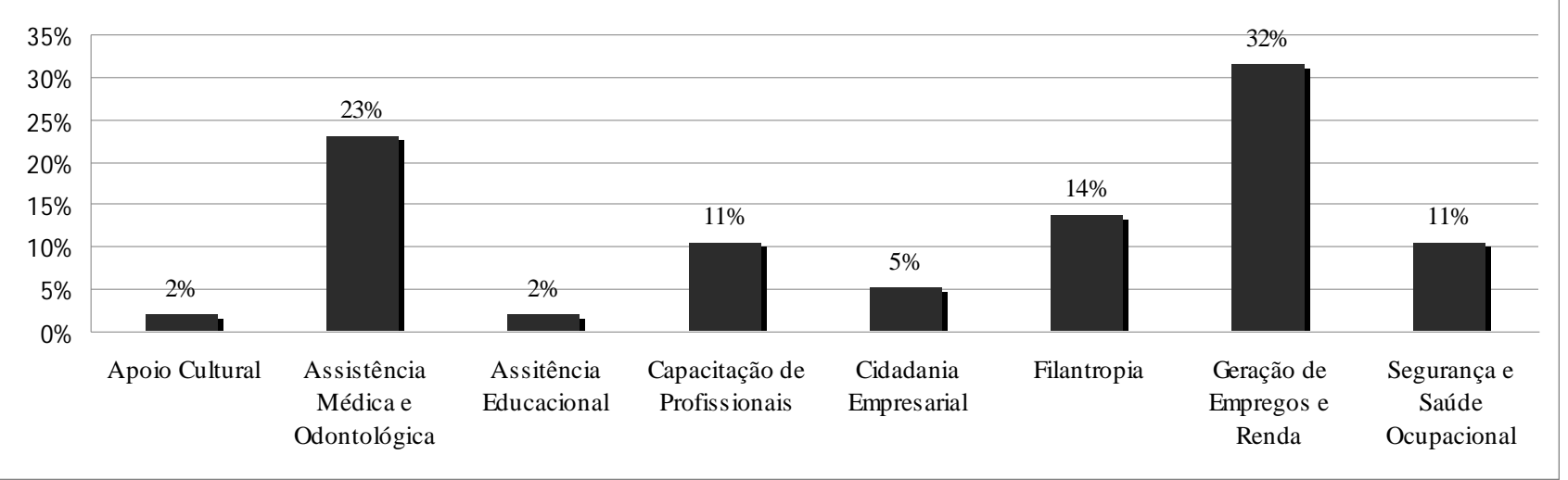

Figura 7: Benefícios: Aspectos Sociais

Fonte: Elaborada pelos autores.

Entre os impactos positivos citados, sobressai-se a referência à "geração de novos empregos". No entanto, éimportante ressaltar que algumas das empresas pesquisadas deixam claro, em seus comentários no DCP e nos depoimentos dos gerentes dos projetos, que os empregos a serem gerados não exigem grandes capacitações profissionais, referindo-se especificamenteà "mãode-obra de baixa qualificação", principalmente nos projetos relacionados à cogeração de energia através da queima do bagaço de cana. Ressalva-se, ainda, que 0 aumento da mão-de-obra pode não estar relacionado com o MDL, mas sim com o momento positivo de aumento da produção de álcool no Brasil, incentivado pelo incremento da frota de carros com tecnologia flex (que aceitam álcool e gasolina) e pela exportação desse biocombustível. lhos envolvidos no projeto, juntamente com a "assistência educacional", citada por $2 \%$ dos projetos avaliados.

Parte-se, agora, para a análise dos Aspectos Econômicos (Figura 08) ligados aos projetos da presente pesquisa. Verificase que, mais uma vez, a geração de empregos, agora sob a denominação "criação de emprego e renda", mereceu grande destaque por parte das empresas proponentes.

O itenta e três por cento (83\%) dos projetos pesquisados indicam quea criação de novos postos de trabalho e a geração de renda para a comunidade é 0 aspecto econômico mais importante trazido pelo projeto. Mais uma vez, é necessário indagarse em que fase do projeto esses empregos estão sendo gerados e qual o grau de complexidade das atividades requeridas. 


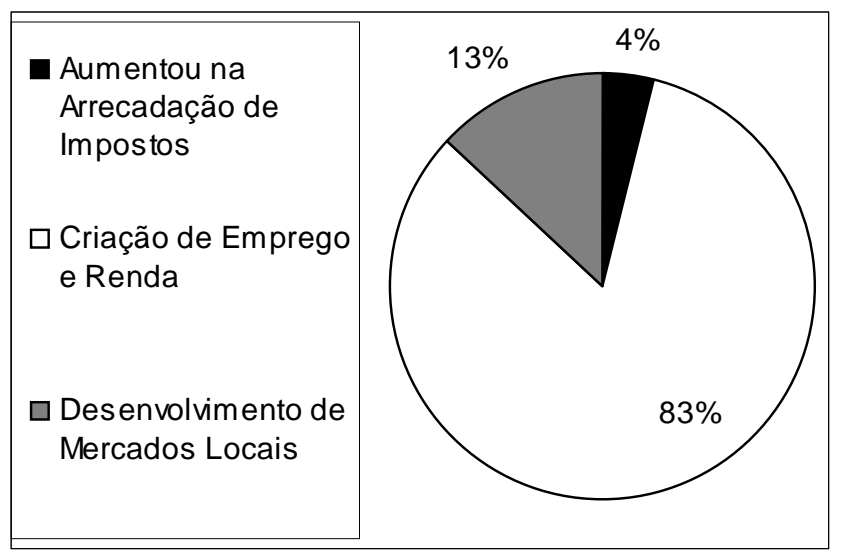

Figura 8: Benefícios: Aspecto Econômico

Fonte: Elaborada pelos autores.

O estímulo a mercados locais, que poderia ser um bom indicativo de contribuição para o desenvolvimento sustentável, aparece em segundo lugar, com somente $13 \%$ das citações. Já 0 aumento na arrecadação de impostos foi citado por apenas $4 \%$ dos projetos investigados.

\section{CONSIDERAÇÕESFINAIS}

0 presente artigo retrata os resultados parciais de um projeto de pesquisa que analisa as contribuições dos projetos de MD L brasileiros para a geração de tecnologias limpas em prol do desenvolvimento sustentável. Nesse momento, apresentaram-se apenas os dados e resultados referentes aos projetos ligados à Indústria de E nergia, escolhido por ser o segmento que mais vem recebendo a atenção do empresariado brasileiro nos projetos de MDL.

Foram analisados - à luz dos conceitos de tecnologia limpa, transferência de tecnologia e desenvolvimento sustentável todos os projetos brasileiros referentes à Indústria de Energia que haviam recebido créditos de carbono até o final de 2007.

Conforme se depreende dos resultados obtidos, não obstante 0 Protocolo de Kyoto estabelecer como obrigatória a cooperação entre os países participantes dos projetos de MD L, através da "transferência de tecnologias ambientalmente seguras" em prol do desenvolvimento sustentável, este artigo defende que - mais do que a "transferência de tecnologias ambientalmente seguras" - énecessário que os projetos de MDL contribuam para a elaboração conjunta de tecnologias limpas entre países financiadores e hospedeiros. Considera-se que não seja eficaz alcançar desenvolvimento limpo mediante transferência de tecnologias apenas ambientalmente seguras, visto que elas podem estar focadas somente na remediação da poluição, e não em sua efetiva prevenção. Para tal, enfatiza-se a necessidade de cooperação ou de parceria entre os países participantes de projetos de MD L para o incremento da capacitação e do desenvolvimento tecnológico nos países fora do Anexo I, pautado pela inovação e pela produção limpa.

Analisando a realidade brasileira referente à contribuição dos projetos de MDL ligados à Indústria de Energia para o desenvolvimento de tecnologias limpas no País, pode-se afir- mar que até o momento essa contribuição é incipiente, visto que de todos os 37 projetos analisados na presente investigação apenas $5 \%$ se caracterizam pela geração de novas tecnologias focadas na produção mais limpa (Figura 5), e em apenas 1\% houve contribuição para a criação de patentes e inovação (Figura 4).

D a mesma forma, considerando que a tecnologia limpaé a mais adequada para alcançar um desenvolvimento mais limpo e sustentável, não se pode afirmar que esses projetos de MD L brasileiros estão efetivamente contribuindo para esse objetivo. Somente em 2,5\% dos projetos estudados houve a preocupação com a diversificação da matriz energética do País (Figura6), enquanto apenas $12 \%$ dos projetos contribuíram para estimular mercados locais (Figura 8) e 5\% dos projetos tiveram como estratégia de responsabilidade social a cidadania empresarial (Figura 7). Assim, a análise dos projetos brasileiros ligados à Indústria de Energia revela que, ao menos no Brasil, o MD L está longe de atingir o objetivo fundamental de, através da cooperação entre países, desenvolver tecnologias que busquem a efetiva redução na fonte dos $\mathrm{GEE}$, minimizando 0 aquecimento climático global e contribuindo para a instituição de um modelo de desenvolvimento mais limpo.

Por fim, recomenda-se a realização de estudos futuros mais amplos sobre a realidade brasileira, incluindo a análise dos projetos de MDL enquadrados em todas as categorias e não apenas na da Indústria de Energia, e posterior comparação com os outros dois principais países hospedeiros (Índia e China) quanto à contribuição desses projetos para a geração de tecnologias limpas em prol do desenvolvimento sustentável.

\section{REFERÊNCIAS}

ALBERTO N, Anete. Meio ambiente e desempenho ecô̂micofinancira. o impacto da ISO 14001 nas empresas brasileiras. 2003.Tese (D outorado em Engenharia de Produção). Programa de Pós-G raduação em Engenharia de Produção (PPGEP), Universidade Federal de Santa Catarina (UFSC). Florianópolis, 2003.

BARBIERI, José Carlos. Gestão ambiental empresarial: conceitos, modelos e instrumentos. São Paulo: Saraiva, 2004.

BATISTA, P.N. 0 desafio brasileiro: a retomada do desenvolvimento em bases ecologicamente sustentáveis. Pdítica Extema, v. 2, n. 3, p. 29-42, dez, 1993.

BRA SIL. LEI № 10.438, de26 deabril de2002. Cria o Programa de Incentivo às Fontes Alternativas de Energia Elétrica (Proinfa). Disponível em: <http:/ / www.aneel.gov.br/ cedoc/ lei200210438.pdf>. Acesso em: 25 jun. 2008.

BUARQUE, S. C. Metoddoga dePlangamento do Desenvdvimento Loal e Mumiäpal Sustentáve. Recife: IICA, 1999. CEPAL, Comisión para América Latina y el Caribe. Informe del Seminário Indicadores de D esarrollo Sostenible en América Latina y el Caribe. Santiago: 2003. CARRIERI, A. de P. O fimdo mmdb Temig a transformação das significações culturais em uma empresa de telecomunicações. 2001. Tese. (D outorado em Administração). D epartamento de Ciências Administrativas, Universidade Federal de Minas Gerais, Minas G erais, 2001.

COMISSÃO INTERMINISTERIAL SOBRE MUDANÇA GLOBAL D O CLIMA (CIMGC). Resdugãon 1. Brasília, setembro de 2003.

ESTY, D aniel C. \& IVANOVA, Maria H. (O rg.) Gldbel Enironmental Govemance options \& opportunities. New Haven, CT: Yale School of Forestry \& Environmental Studies, 2002 
G RAU-NETO, W. O Protocolo de Quicto e o Mecanismo de Desenvivimento Limpo - MDL: uma análise crítica do Instituto. São Paulo: Fiúza, 2007.

LaGREGA, M. D.; BUCKINGHAM, P. L.; EVANS, J. C. The Environmental Resources Management Group. In:

Hazardaus Waste Management. Singapore: McG raw-Hill, $19 \overline{9} \overline{4}, \overline{1} \overline{1} \overline{\mathrm{p}}$.' GOLDEMBERG, J. O Caminho até Joanesburgo. In: TRIG UEIRO, André (Coord.). Méo ambiente no séullo 21: 21 especialistas falam da questão ambiental nas suas áreas de conhecimento. Rio de Janeiro: Sextante, 2005.

KIPERSTOK, Asher (Coord.). Inovação e mio ambiente elementos para o desenvolvimento sustentável na Bahia. Salvador: Centro de Recursos Ambientais, 2003. (Série Construindo os Recursos do Amanhã).

KIPERSTOK, Asher et al. Prevenção da Pduiçãa Brrasília: SENAI/ D N, 2002. 290 p.il. (Programa SENAI Educação a Distância. Tecnologias e G estão Ambiental - TGA ).

KUHN, T. A. Estrutura das Revduçaes Científicas 3 ed. São Paulo, Ed. Perspectiva, 2003.

LENZI, Cristiano Luís. Sodidoja ambiental: risco e sustentabilidade na modemidade. São Paulo: Edusc, 2006.

LE PRESTRE, Philippe. Protection de l'environnement \& relations intemationales les défis de l'écopolitique mondiale. Paris : Armand Colin, 2005.

MILANI, C. R. S.; KERAG HEL, C. The International Agenda for Sustainable D evelopment: International Contestatory Movements. In: THOYER, Sophie; MARTIMORT, Benoit. (O rg.). Partiapation for Sustainability in Trade 1 ed. Londres: Ashgate Publishers, 2007, v. 1, p. 93-109.

MINISTÉRIO DA CIÊNCIA E TECNOLOGIA (MCT), Status atual das atividades de projeto no âmbito do Mecanismo de D esenvolvimento Limpo (MDL) no Brasil e no Mundo. In: Mudanças Climáticas D isponível em <http:/ / www.mct.gov.br/ index.php/ content/ view/ 30317.html>. Acesso em: 05 jan. 2009.

MOTTA, Paulo Roberto; G UIMARÃES, Roberto (coord.). O mercado decarbona de Q uioto a Bali. Rio de Janeiro: Fundação G etúlio Vargas, 2008.

NETO, P. Govemança e o Ecocompromeimento promovendo Desenvivimento Sustentávd a partir da Gestão de Rearsos Hídricos: 0 caso da Aracruz/ Unidade Guaíba e seus stakeholders. Disponível em: <http:/ / volpi.ea.ufrgs.br/ teses_e_dissertacoes/ td/ 001319.pdf> .Acesso em: 29. abr. 2004.

PHILIPPI, D. A. e ERD MANN, R. H. A Produção mais Limpa, o Planejamento da Produção e o D esenvolvimento Sustentável. In: ENCONTRO NACIONAL DE GESTÃO EMPRESARIAL E MEIO AMBIENTE, 9, 2007, Curitiba, Anais.. Curitiba: UNICENP, FEA (USP), EAESP (FGV-SP) e EBAPE (FGV-RJ), 2007.

SACHS, I. Estratégias de Transição para o Séaulo XXI. São Paulo: Nobel, 1993.

SACHS, I. Pensando Sobre D esenvolvimento Na Era Do Meio Ambiente. In STRO H, P. Y. (O rg). Caminhos para o desenvdvimento sustentáved. Rio de Janeiro: Grammond, 2002.

SENAD O FEDERAL. ProtododeQuidoelegjsaçãocomdata Brasília: Senado Federal Subsecretariado de Edições Técnicas. Coleção Ambiuental, vol. 3. 2004

SERES, Stephen. Analysis of Tedndogy Transfer in CDM Projets. UNFCCC. (2007). D isponível em: http:/ / cdm.unfccc.int/ Reference/ Reports/ TTreport/ report1207.pdf . Acesso em: 29 D ez 2008.
SILVA FILHO, J. C. L. O Papel das ONG 's na D ifusão de Inovações Tecnológicas Ambientais. In: SeminánioLatimoIbercamericanodeGestion Temdogica, 7, 1999, Valencia. Anais (CD RO M), 1999.

WBCSD. World Busines Council for Sustainable D evelopment. Eœ efiênia: criar mais valor com menos impacto. Disponível em: http\\www.wbscd.org.>. A cesso em: 03/ 12/ 2008.

UNFCCC. CDM Statistics D isponível em <http:/ / cdm.unfccc.int/ Statistics/ index.html >. Acesso em: 05 jan. 2009

VENTURA, A. C. Mecanismo de desenvivimento limpo (MDL): uma análise da regulação dos conflitos socioambientais. 2008. 227f. Dissertação (Mestrado em Administração) - Escola de Administração, Universidade Federal da Bahia, Salvador, 2008.

Data de Submissão: 10/ 08/ 2009

Data de Aprovação: 18/ 03/ 2010 